\title{
Study on PI Parameters Dynamic Tuning Based on Ant Colony Algorithm for Doubly-fed Wind Turbines
}

\author{
Bo Gu, Xiaodan Li, Daoyin Qiu and Lingyun Zhang \\ School of electric power, North China University of Water Conservancy and Electric \\ Power, Zhengzhou, 450011, China \\ fslxd2006@gmail.com,gb1982@ncwu.edu.cn
}

\begin{abstract}
For the shortcoming that the PI controller parameters can't been dynamic tuning in constant voltage control system of doubly-fed wind turbines, a PI controller parameters dynamic tuning strategy based on the ant colony optimization (ACO) algorithm is presented. This strategy makes the two parameters in PI controller as the ant of the ant colony, the controlled absolute error integral function that between terminal voltage actual value and its reference value for doubly-fed wind turbines is selected as the optimization objective, the PI controller parameters dynamically is adjusted in the control process. When the wind speed changes and the grid voltage drops, the dynamic and non-dynamic parameter tuning methods are compared and analyzed. The simulation results show that the constant voltage control system using the PI controller parameters tuning strategy based on the ant colony optimization algorithm is superior to non-dynamic tuning method on the stability and response time of system.
\end{abstract}

Keywords: doubly-fed wind turbines, constant voltage control system, ant colony optimization algorithm, parameter dynamic tuning

\section{Introduction}

Wind energy is a clean and renewable energy. Under the condition of today's energy shortage and environment problem, wind power generation has been paid more and more attention [1-2]. The output power of wind turbines is affected by the wind speed. Due to the characteristics of randomness and variability of wind speed, the output power of wind turbine changes with time. At the same time the wind farms are commonly located in remote areas, so the change of its out power poses an adverse affect on the stability of the grid-connected voltage for wind farms. For a higher proportion of wind farms in power system, the disconnection of wind turbines may cause the collapse of the grid voltage and frequency when the grid voltage drops to a certain value, and that may bring many adverse consequences [3]. Technical rule for connecting a wind farm to a power network explicitly requests that the reactive power-voltage control system should be configured in grid-connection wind farm, and this system controls the grid-connection voltage at the rated voltage of $97 \%$ to $107 \%$.

Doubly-fed wind turbines with independent, flexible and reactive power regulation can realize the control of the double fed wind farm grid voltage [4-5]. Doubly-fed wind turbines have two kinds of operation mode, which are the constant power factor and constant voltage control respectively, the stability of the power system voltage can be guaranteed when that use constant voltage control mode [6-7]. The control strategy is presented which uses the 
Nyquist constraint algorithm to design optimization PI controller [8]; this method without additional reactive power compensation device improves the performance of the voltage control system, but it can't realizes the dynamic tuning of PI parameters in the case of wind speed changing or grid failure. The electromagnetic torque and stator instantaneous power of doubly-fed wind turbines would oscillate when the grid voltage is in imbalance, so the method was presented which uses the vector PI controller to eliminate the electromagnetic torque and stator instantaneous power's oscillation [9]. In order to improve the performance constant voltage control system, a new method which introduces the equivalent wind speed as the feed forward control parameter was presented in [10]; this method can effectively restrain the voltage fluctuation because of the wind speed changes. The above authors have being studied PI controller of the constant voltage control system, but their study were mainly in achieving the optimal PI parameters of the constant voltage control system in the steady state. Whether the PI controller parameters need to be adjusted dynamically and how to be adjusted in changing wind speed and grid voltage drooping state, these authors didn't give definitive conclusions.

In the present paper, a PI controller parameters dynamic tuning strategy based on the ant colony optimization (ACO) algorithm is presented, in this strategy, the two parameters in PI controller are selected as the ant of the ant colony, the controlled absolute error integral function that between terminal voltage actual value and its reference value for doubly-fed wind turbines is selected as the optimization objective, to adjusts the PI controller parameters dynamically in the control process. The dynamic parameter tuning method and non-dynamic parameter tuning method are compared and analyzed when the wind speed is changing and the grid voltage drooping.

\section{The Power Decoupling Control Principle of Doubly-fed Wind Turbines}

The steady state mathematical model of doubly-fed wind turbines was established under the synchronous rotating $d, q$, and $O$ coordinate system according to the doubly-fed wind turbines' equivalent model. The steady state voltage equation and flux linkage equation can be obtained as shown in equation (1) and equation (2).

$$
\begin{gathered}
\left\{\begin{array}{l}
U_{d s}=-r_{s} I_{d s}-\psi_{q s} \\
U_{q s}=-r_{s} I_{q s}+\psi_{d s} \\
U_{d r}=r_{r} I_{d r}-s \psi_{q r} \\
U_{q r}=r_{r} I_{q r}+s \psi_{d r}
\end{array}\right. \\
\left\{\begin{array}{l}
\psi_{d s}=-L_{s s} I_{d s}+L_{m} I_{d r} \\
\psi_{q s}=-L_{s s} I_{q s}+L_{m} I_{q r} \\
\psi_{d r}=L_{r r} I_{d r}-L_{m} I_{d s} \\
\psi_{q r}=L_{r r} I_{q r}-L_{m} I_{q s}
\end{array}\right.
\end{gathered}
$$

In equation (1) and (2), $U_{d s}$ and $U_{q s}$ is the doubly-fed wind turbines stator voltage $d q$ axis component respectively; $U_{d r}$ and $U_{q r}$ is $d q$ axis components of the rotor voltage respectively; Ids and $I_{q s}$ is the $d q$ axis component of the stator winding current respectively; $I_{d r}$ and $I_{q r}$ is the $d q$ axis component of the rotor winding current respectively; $\psi_{d s}$ and $\psi_{q s}$ is the $d q$ axis component of the stator flux linkage respectively; $\psi_{d r}$ and $\psi_{q r}$ is $d q$ axis component of the rotor flux linkage respectively. $s$ is the slip of the doubly-fed wind turbines, $L_{r r}=L_{r}+L_{m}, L_{s s}=$ $L_{s}+L_{m}$. The $d$ axis component of the synchronous rotating coordinate system is located in 
the stator synthesis flux linkage, so the synthesis flux linkage $\psi_{s}$ of stator is equal to $\psi_{d s}$, and $\psi_{q s}=0$. When the stator resistance is ignored, equation (3) can be gotten.

$$
\left\{\begin{array}{l}
U_{d s}=0 \\
U_{q s}=U_{s}
\end{array}\right.
$$

According to equation (2), the current relationship between the stator and the rotor can be expressed as equation (4).

$$
\left\{\begin{array}{l}
I_{q s}=-\frac{L_{m}}{L_{s s}} I_{q r} \\
I_{d s}=-\frac{U_{s}}{L_{s s}}+\frac{L_{m}}{L_{r r}} I_{d r}
\end{array}\right.
$$

The stator active power and reactive power can be expressed as equation (5).

$$
\left\{\begin{array}{l}
P_{s}=U_{d s} I_{d s}+U_{q s} I_{q s}=U_{s} I_{q s} \\
Q_{s}=U_{q s} I_{d s}-U_{d s} I_{q s}=U_{s} I_{d s}
\end{array}\right.
$$

From the above analysis, the active and reactive power can be adjusted by control $d$ axis and $q$ axis component of rotor current, to realize the power decoupling control.

\section{The Constant Voltage Control System Principle}

It is has be known that the vector control based on stator flux linkage oriented of the doubly-fed wind turbines can realize the power decoupling control, therefore, the control of terminal voltage of the doubly-fed wind turbines can be realized by using the rotor side converter. From the equation (4) and (5), the reactive power $Q_{\text {grid }}$ of wind farm delivered to the grid can be gotten.

$$
Q_{\text {grid }}=Q_{s}=U_{s} I_{d s}=-\frac{U_{s}^{2}}{L_{s s}}+\frac{L_{m} U_{s}}{L_{s s}} I_{d r}
$$

In equation (6), the rotor current component $I_{d r}$ can be divided into two parts, one part is the excitation current of the generator $I_{d r_{-} m}$, the other is $I_{d r_{-} g}$ is used to control the reactive power exchanging with the grid. Therefore, the total reactive power can be divided into two parts $Q_{m a g}$ and $Q_{g e n}$, these are shown in equation (7).

$$
\left\{\begin{array}{l}
Q_{m a g}=-\frac{U_{s}^{2}}{L_{s s}}+\frac{L_{m} U_{s}}{L_{s s}} I_{d r_{-} m} \\
Q_{g e n}=\frac{L_{m} U_{s}}{L_{s s}} I_{d r_{-} g}
\end{array}\right.
$$

Because the terminal voltage varies with the injected grid reactive power changes, so the constant voltage control must meet two requirements:

1) The consumption reactive power by doubly-fed induction generator (DFIG) should be compensated by $I_{d r_{-} m}$;

2) Compared with reference values, if the terminal voltage is too high or too low, the $I_{d r_{-} g}$ should make corresponding adjustment.

Therefore, in constant voltage control mode $I_{d r_{-g}}$ can make corresponding adjustment to raise or reduce the reactive power when the grid voltage has a little change, so as to maintain the terminal voltage is approximately the same. Figure 1 is a schematic diagram of the constant voltage control system, $U_{s}$ is the terminal voltage of the doubly-fed wind turbines, $U_{s_{-} r e f}$ is the reference value of the doubly-fed wind turbines' terminal voltage, for double fed 
wind generator terminal voltage reference value, $U_{s_{-} r e f}=1 \mathrm{pu}$ in simulating, the PI controller is adopted in the control system.

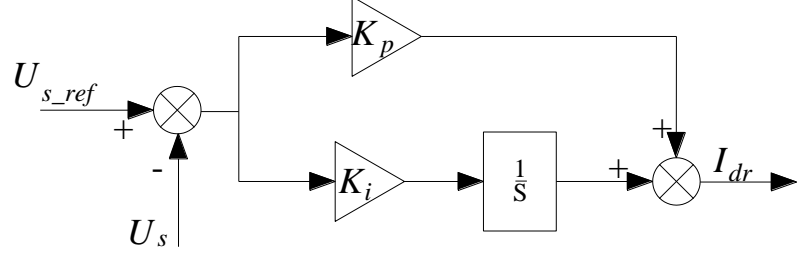

Figure 1. The schematic diagram of the constant voltage control system

\section{Parameter Optimization of PI Controller based on Ant Colony Algorithm}

Ant colony algorithm is a new bionic optimization algorithm; it is optimization in a series of combinatorial optimization problems. The distributed feedback and parallel mechanism is used to speed up the evolution process in a certain extent, and find the optimal solution [12-14]. The positive feedback mechanism is that more ants walk on a path, then other ants choose the path probability is larger, individual ant is through this method to exchange information and search for food, and finally finds the shortest path to search for food. The traditional PI controller parameters $K_{p}$ and $K_{i}$ once are determined, they are remained constant in the adjusting process of constant voltage control system of the doubly-fed Wind Turbines, in this case, the PI controller is hard to meet the requirement to quickly adapt the change of system and The system disturbance rejection when the wind speed and power grid operation state changes. In order to solve this problem, this paper presents ant colony optimization algorithm for constant voltage control system parameters $K_{p}$ and $K_{i}$ optimization, the ant colony optimization algorithm implements adaptive PI controller and improves the stability that the DFIG connects to grid system.

\subsection{The structure of PI controller based on ant colony optimization algorithm}

Figure 2 is the PI controller structure diagram of doubly-fed wind turbines' constant voltage control system based on ant colony algorithm.

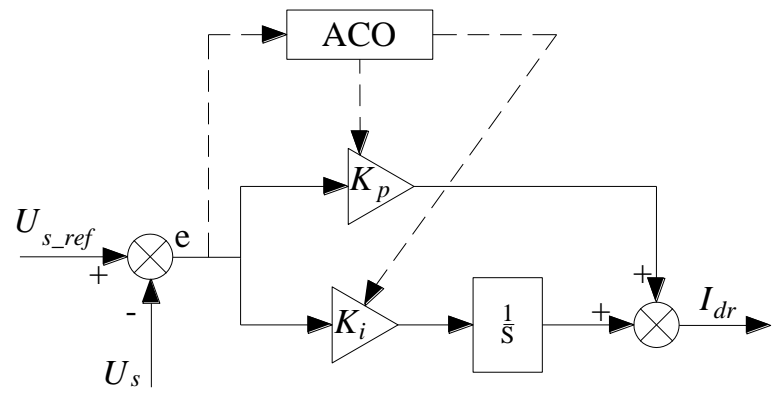

Figure 2. The structure of PI controller based on ACO algorithm

In Figure 2,e is the difference of voltage reference value $U_{s_{-} r e f}$ and terminal voltage $U_{s}$, which is the input signal of ant colony optimization PI controller. In order to ensure smaller overshoot of the error signal transient response, and there is sufficient damping of the oscillation effect, the product integral criterion of time and absolute error is selected as the objective function in this paper. It is shown in equation (8). 


$$
F=\int_{0}^{t} t|e(t)| d t
$$

The convergence criterion is shown in equation (9).

$$
\left|\frac{J_{\text {max }}-J_{\text {min }}}{J_{\text {min }}}\right|<\varepsilon
$$

In the equation (9), $J_{\max }$ is the maximum point of optimization; $J_{\min }$ is the minimum value point of optimization; $\varepsilon$ is a given error value. When the whole ants converge to the same path, then the algorithm ends, the path is the optimal path; the optimal path corresponds to the optimal parameters of PI controller.

\subsection{Ant colony algorithm node and path generation}

The optimization problem of the ant colony algorithm must be mapped to a weighted graph, so the ants can find an optimal solution in the whole feasible region [15]. The 2 parameters $K_{p}$ and $K_{i}$ of PI controller are selected as the variable to be optimized in the constant voltage control system, the initial value of $K_{p}$ and $K_{i}$ can be gotten by using Ziegler-Nichols method [16], which is $K_{p}=1.25$ and $K_{i}=300$, thus the variable to be optimized $K_{p}$ and $K_{i}$ is set 3 significant digit respectively. In order to facilitate use of ant colony algorithm, the values of the 2 parameters $K_{p}$ and $K_{i}$ are mapped to the weighted graph, weighted graph structure is shown in Figure 3.

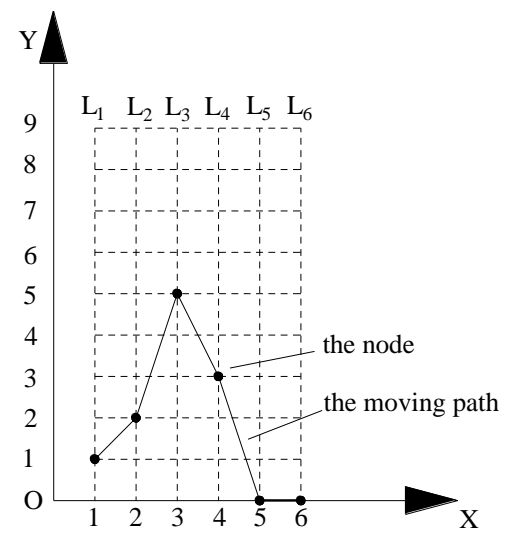

Figure 3. The weighted graph of ant colony algorithm

In Figure 6, there are 6 lines $L_{1}, L_{2} \ldots L_{6}$, which are at equal intervals, equal length and perpendicular to the $\mathrm{X}$ axis, Where $L_{1} \sim L_{3}$ and $L_{4} \sim L_{6}$ represents $1 \sim 3$ digits of $K_{p}$ and $K_{i}$ respectively. The 6 lines are divided into 9 equal portions respectively, each line has 10 modes which represent the line may be achieved 10 values $(0,1 \ldots 9)$. Each node in the weighted graph is represented by knot $\left(x_{i}, y_{i, j}\right)$, Where $x_{i}$ is the abscissa of the line $L_{i}, y_{i, j}$ is the ordinate of node $j$ on the line $L_{i}, i=1 \sim 6, j=0 \sim 9$.

Assuming an ant starts from the coordinate origin $O$, when it creeps into any one node of line $L_{6}$, one cycle is completed, the crawling path can be expressed as: path $=\left\{O, \operatorname{knot}\left(x_{1}, y_{1}\right.\right.$, $\left.\left.{ }_{j}\right), \operatorname{knot}\left(x_{2}, y_{2, j}\right) \ldots, \operatorname{knot}\left(x_{6}, y_{6, j}\right)\right\}$, where the node $\operatorname{knot}\left(x_{i}, y_{i, j}\right)$ is located in the line $L_{i}$. This path represents $K_{p}$ and $K_{i}$ value can be calculated as equation (10). 


$$
\left\{\begin{array}{l}
K_{p}=\sum_{i=1}^{3} y_{i, j} \cdot 10^{1-i} \\
K_{i}=\sum_{n=4}^{6} y_{n, j} \cdot 10^{6-n}
\end{array}\right.
$$

Assuming that each ant's crawling time from any point on line $L_{i}$ to any point on line $L_{i+1}$ is equal, it is independent for the distance between the nodes. So, if all the ants start from the origin of coordinates $O$, they will arrive each line $L_{i}(i=1 \sim 6)$ at the same time, and finally arrive their destination nodes on $L_{6}$ at the same time, this cycle is completed.

\subsection{Path selection of ant colony algorithm}

The ants move to line $L_{i}$ at time t, let $b_{j}(j=0 \sim 9)$ is the number of ants for node $j$ in $L_{i}$ at time $\mathrm{t}$, the total ants $\mathrm{m}$ can be expressed as $m=\sum b_{j}(t)$. Let $\tau\left(x_{i}, y_{i, j}, t\right)$ expresses the left pheromone in the node $\operatorname{knot}\left(x_{i}, y_{i, j}\right)$ at time $\mathrm{t}$, the amount of information on each node is equal at initial time, i. e. $\tau\left(x_{i}, y_{i, j}, 0\right)=\mathrm{c}$, where c is a constant, $\Delta \tau\left(x_{i}, y_{i, j}, 0\right)=0$. Let $P_{k}\left(x_{i}, y_{i, j}, t\right)$ expresses the state transition probability of the $\mathrm{k}$ ant when it crawls from any one node of line $L_{i-1}$ to node $\operatorname{knot}\left(x_{i}, y_{i, j}\right)$ at time t, $P_{k}\left(x_{i}, y_{i, j}, t\right)$ is shown as equation (11).

$$
P_{k}\left(x_{i}, y_{i, j}, t\right)=\frac{\tau^{\alpha}\left(x_{i}, y_{i, j}, t\right) \eta^{\beta}\left(x_{i}, y_{i, j}, t\right)}{\sum_{j=0}^{9} \tau^{\alpha}\left(x_{i}, y_{i, j}, t\right) \eta^{\beta}\left(x_{i}, y_{i, j}, t\right)}
$$

In equation (11), $\alpha$ is the information inspiring factor, it shows the effect of the ant accumulated information during the movement when the ant is moving. The value of $\alpha$ is larger, then the possibility that the ant selects the previously traversed path is greater; $\beta$ is the desired heuristic factor, it reflects the relative importance of the heuristic information which guides the ants in the search process, the size of the value $\beta$ reflects the intensity of a priori and certainty factor on ant colony optimization process, $\eta\left(x_{i}, y_{i, j}, t\right)$ is the heuristic function of node $\operatorname{knot}\left(x_{i}, y_{i, j}\right)$ which is shown as equation (12).

$$
\eta\left(x_{i}, y_{i, j}, t\right)=\frac{10-\left|y_{i, j}-y_{i, j}^{*}\right|}{10}
$$

In equation (12), the value of $y_{i, j}^{*}(i=1 \sim 6, j=0 \sim 9)$ is the following way: In the first cycle of the ant colony algorithm, the value of $y_{i, j}^{*}$ is the each node ordinate values that is the initial PI controller parameters $K_{p 0}$ and $K_{i 0}$ values mapped on weighted graph; in the subsequent cycles, $y_{i, j}^{*}$ is the each node ordinate values that the optimal path corresponding to the PI controller parameters $K_{p}^{*}$ and $K_{i}^{*}$ value mapped on weighted graph.

In order to avoid too much residual information caused by residual pheromone floods the heuristic information, each ant completes a cycle creeping, the residual pheromone on the node of the path should be updated. Thus, the amount of information on node knot $\left(x_{i}, y_{i, j}\right)$ at $t+n$ time should be adjusted according to the equation (13).

$$
\begin{gathered}
\tau\left(x_{i}, y_{i, j}, t+n\right)=(1-\rho) \tau\left(x_{i}, y_{i, j}, t\right)+\Delta \tau\left(x_{i}, y_{i, j}, t\right) \\
\Delta \tau\left(x_{i}, y_{i, j}, t\right)=\sum_{k=1}^{m} \Delta \tau_{k}\left(x_{i}, y_{i, j}\right)
\end{gathered}
$$

In equation (13), $\rho$ is the pheromone evaporation factor; $1-\rho$ is the pheromone residue factor, in order to prevent infinite accumulation of pheromone, the range of $\rho$ value is $\rho$ $\subset[0,1) ; \Delta \tau\left(x_{i}, y_{i, j}, t\right)$ is the pheromone increment on node $k n o t\left(x_{i}, y_{i, j}\right)$ in this cycle; $\Delta \tau\left(x_{i}\right.$, $\left.y_{i, j}\right)$ is the pheromone on node $\operatorname{knot}\left(x_{i}, y_{i, j}\right)$ of the $k$-th ant in this cycle. The equation of $\Delta \tau$ $\left(x_{i}, y_{i, j}\right)$ is as following. 


$$
\Delta \tau_{k}\left(x_{i}, y_{i, j}\right)=\left\{\begin{array}{l}
Q / F_{k}, \quad \text { The ant passes through the node } \operatorname{knot}\left(x_{i}, y_{i, j}\right) \\
0, \quad \text { The ant doesn't pass through the node } \operatorname{knot}\left(x_{i}, y_{i, j}\right)
\end{array}\right.
$$

In equation (15), $Q$ is the pheromone intensity, which stands for the total amount of pheromone released on the path when the ant completes a cycle creeping. The bigger value of $Q$, the faster pheromone accumulates over the path that the ant has experienced. And the bigger value of $Q$ also contributes to accelerate the convergence. $F_{k}$ is the objective function value of $k$-th ant in the loop.

\subsection{The steps of PI parameters optimization using by the ant colony algorithm}

According to the analysis of the basic principle of ant colony algorithm, the steps of PI parameters optimization using by the ant colony algorithm can be summarized as follow.

1) To get the PI controller parameters $\left(K_{p 0}, K_{i 0}\right)$ of the constant voltage control system for doubly-fed wind power generator by using Ziegler - Nichols method.

2) To set the number of ants $m$, and to define the one-dimensional array $p^{2} a t h_{k}$ which has six elements for each ant $k(k=1 \sim m)$. The six nodes ordinate values that the $k$-th ant has passed are stored in path $_{k}$, which can be used to represent the crawling path of the $k$-th ant.

3) To set the time counter $t=0$ and the cycle number $N_{c}=0$, and to set the maximum cycle number $N_{c \max }$ and the pheromone value $c$ of each node $\left(x_{i}, y_{i, j}, 0\right)$ in the initial time. To make $\Delta \tau\left(x_{i}, y_{i, j}\right)=0$, and put all the ant at the coordinate origin $O$.

4) Setting $i=1$.

5) The probability for those ants transit to each node on the line $L_{i}$ are calculated by the formula (11). According to these probabilities, a node on the line $L_{i}$ is selected for each ant $k$ by using the roulette wheel selection method, and then the ant $k$ is moved to the node. The ordinate value of this node is stored as $i$-th element in the path $_{k}$.

6) Setting $i=i+1$, if $i \leq 6$, then jump to step 5, otherwise jump to step 7 .

7) According to the path experienced by the ant $k$, namely the array $p^{2} t_{k}$, the PI controller parameters $K_{p}^{k} 、 K_{I}^{k}$ corresponding to the path are calculated by using the equation (10). The objective function value $F_{k}$ corresponding to the ant $k$ is calculated by using the equation (8), and the convergence value $\varepsilon_{k}$ is calculated by using the equation (9). To record the optimal path in this cycle, and its corresponding PI controller parameters are stored in $K_{p}^{*} 、 K_{i}^{*}$.

8) Making $t \leftarrow t+6, N_{c} \leftarrow N_{c}+1$, the amount of pheromone to each node is updated according to the equation (13) (15), and all the elements in the array $p^{a t h} h_{k}$ are cleared.

9) If $N_{c}<N_{c \max }$ and the entire colony has not converged to passing the same path, then all the ants are setting at the coordinate origin $O$ again and jump to step 4. If $N_{c}<N_{c \max }$ and the entire colony has converged to passing the same path or $\varepsilon<$ the given error, then the algorithm terminates, the optimal path and its corresponding optimal PI controller parameters $K_{p}^{*} 、 K_{I}^{*}$ are outputted at last. 


\section{The Algorithm Analysis and Comparison}

Based on the theory above to build a simulation model of the doubly-fed wind turbines, the capacity of a doubly-fed wind turbine is $1.5 \mathrm{MW}$ and its terminal voltage is $575 \mathrm{~V}$. The step-up transformer makes the $575 \mathrm{~V}$ rise to $25 \mathrm{kV}$, and after $30 \mathrm{~km}$ transmission line $25 \mathrm{kV}$ has increased to $120 \mathrm{kV}$ by the second step-up transformer, and then supplies the power to $120 \mathrm{kV}$ grid. The reference voltage of terminal voltage has maintained at $1 \mathrm{pu}$ in the simulation model. The simulation analysis have been done respectively using self-tuning PI control algorithm and classical PI control algorithm in case of wind speed change and grid voltage sag at $t=5 \mathrm{~s}$. The parameter settings of the ant colony optimization algorithm in this design are shown in Table 1.

Table.1 The setting of each parameter in ACO

\begin{tabular}{|l|c|l|c|}
\hline The size of colony $(m)$ & 10 & The maximum cycle number $($ Ncmax $)$ & 100 \\
\hline The pheromone evaporation factor $(\rho)$ & 0.5 & The amount of initial pheromone $(c)$ & 0.2 \\
\hline The information inspiring factor $(\alpha)$ & 3 & The given error $(\varepsilon)$ & 0.001 \\
\hline The desired heuristic factor $(\beta)$ & 2 & The pheromone intensity $(Q)$ & 20 \\
\hline
\end{tabular}

When the wind speed changes from $8 \mathrm{~m} / \mathrm{s}$ to $10 \mathrm{~m} / \mathrm{s}$ at $t=5 \mathrm{~s}$, the dynamic change diagram of rotor current $I_{d r}$ is shown in Figure 4. The solid line corresponds to the self-tuning PI control strategy based on the ant colony optimization algorithm and its tuned parameters are $K_{p}=5.46$ and $K_{i}=405$. The dotted line corresponds to the classical PI control algorithm and its parameters are $K_{p}=1.25$ and $K_{i}=300$.

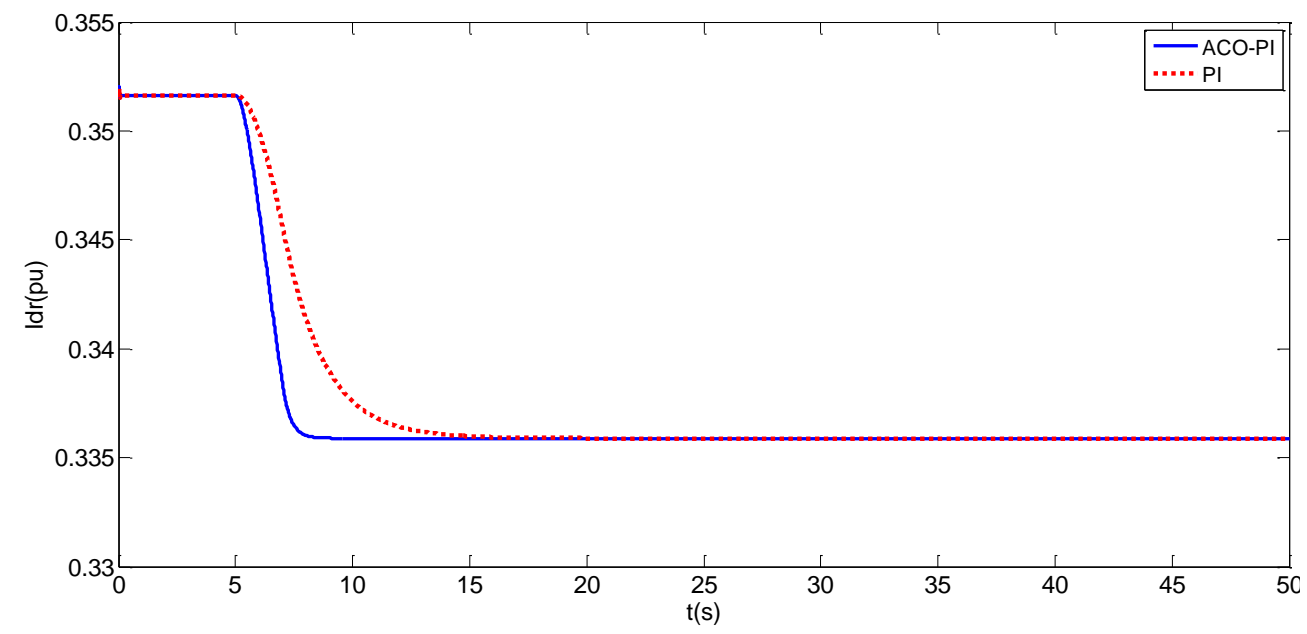

Figure 4. The Dynamic Change Diagram of $I_{d r}$ When Wind Speed Changes from $8 \mathrm{~m} / \mathrm{s}$ to $10 \mathrm{~m} / \mathrm{s}$

The simulation results shown that when the wind speed changes from $8 \mathrm{~m} / \mathrm{s}$ to $10 \mathrm{~m} / \mathrm{s}$ at $t=5 \mathrm{~s}$, the self-tuning PI control strategy based on the ant colony optimization algorithm makes the response time of $I_{d r} 7.47 \mathrm{~s}$ earlier than the classical PI control algorithm.

When the wind speed changes from $8 \mathrm{~m} / \mathrm{s}$ to $10 \mathrm{~m} / \mathrm{s}$ at $t=5 \mathrm{~s}$, the dynamic change diagram of terminal voltage $U_{s}$ for wind turbines is shown in Figure 5. The solid line corresponds to the self-tuning PI control strategy based on the ant colony optimization algorithm and its tuned 
parameters are $K_{p}=5.46$ and $K_{i}=405$. The dotted line corresponds to the classical PI control algorithm and its parameters are $K_{p}=1.25$ and $K_{i}=300$.

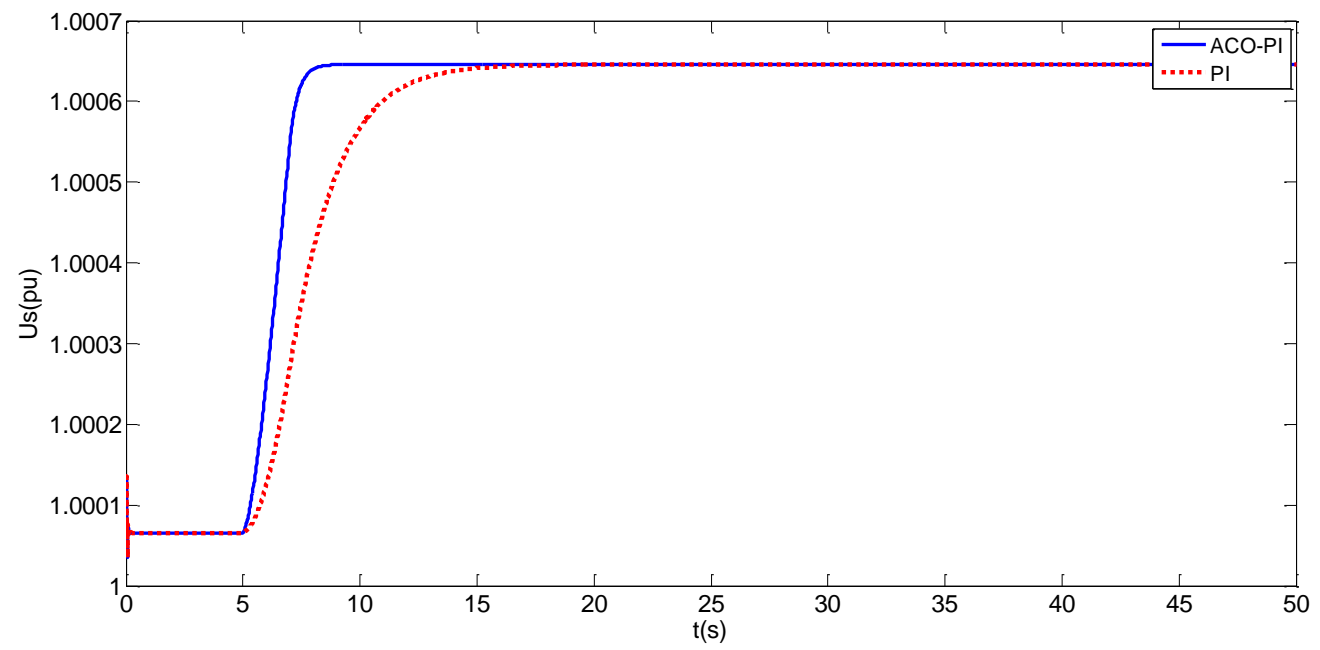

Figure 5. The Dynamic Change Diagram of $U_{s}$ When Wind Speed Changes from $8 \mathrm{~m} / \mathrm{s}$ to $10 \mathrm{~m} / \mathrm{s}$

The simulation results shown that when the wind speed changes from $8 \mathrm{~m} / \mathrm{s}$ to $10 \mathrm{~m} / \mathrm{s}$ at $t=5 \mathrm{~s}$, the self-tuning PI control strategy based on the ant colony optimization algorithm makes the response time of $U_{s} 7.61 \mathrm{~s}$ earlier than the classical PI control algorithm.

When the wind speed changes from $10 \mathrm{~m} / \mathrm{s}$ to $12 \mathrm{~m} / \mathrm{s}$ at $t=5 \mathrm{~s}$, the dynamic change diagram of rotor current $I_{d r}$ is shown in Figure 6. The solid line corresponds to the self-tuning PI control strategy based on the ant colony optimization algorithm and its tuned parameters are $K_{p}=5.23$ and $K_{i}=300$. The dotted line corresponds to the classical PI control algorithm and its parameters are $K_{p}=1.25$ and $K_{i}=300$.

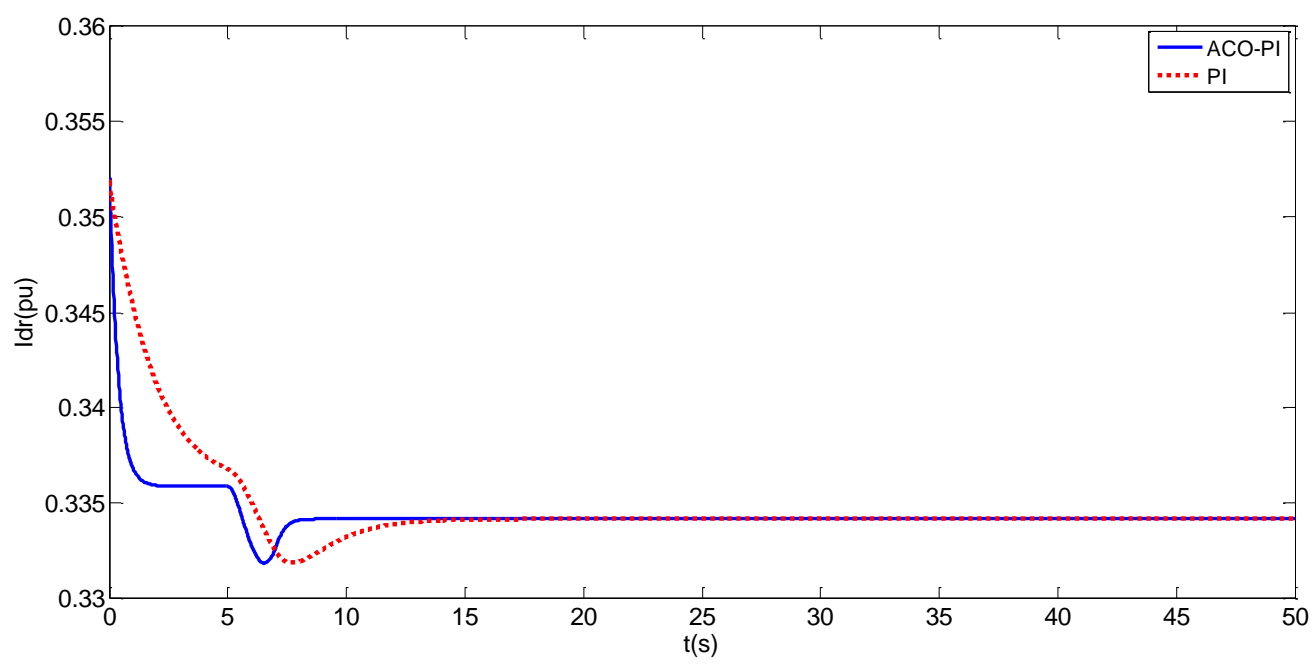

Figure 6. The Dynamic Change Diagram of $I_{d r}$ When Wind Speed Changes from $10 \mathrm{~m} / \mathrm{s}$ to $12 \mathrm{~m} / \mathrm{s}$ 
The simulation results shown that when the wind speed changes from $10 \mathrm{~m} / \mathrm{s}$ to $12 \mathrm{~m} / \mathrm{s}$ at $t=5 \mathrm{~s}$, the self-tuning PI control strategy based on the ant colony optimization algorithm makes the response time of $I_{d r} 6.91 \mathrm{~s}$ earlier than the classical PI control algorithm.

When the wind speed changes from $10 \mathrm{~m} / \mathrm{s}$ to $12 \mathrm{~m} / \mathrm{s}$ at $t=5 \mathrm{~s}$, the dynamic change diagram of terminal voltage $U_{s}$ for wind turbines is shown in Figure 7. The solid line corresponds to the self-tuning PI control strategy based on the ant colony optimization algorithm and its tuned parameters are $K_{p}=5.23$ and $K_{i}=300$. The dotted line corresponds to the classical PI control algorithm and its parameters are $K_{p}=1.25$ and $K_{i}=300$.

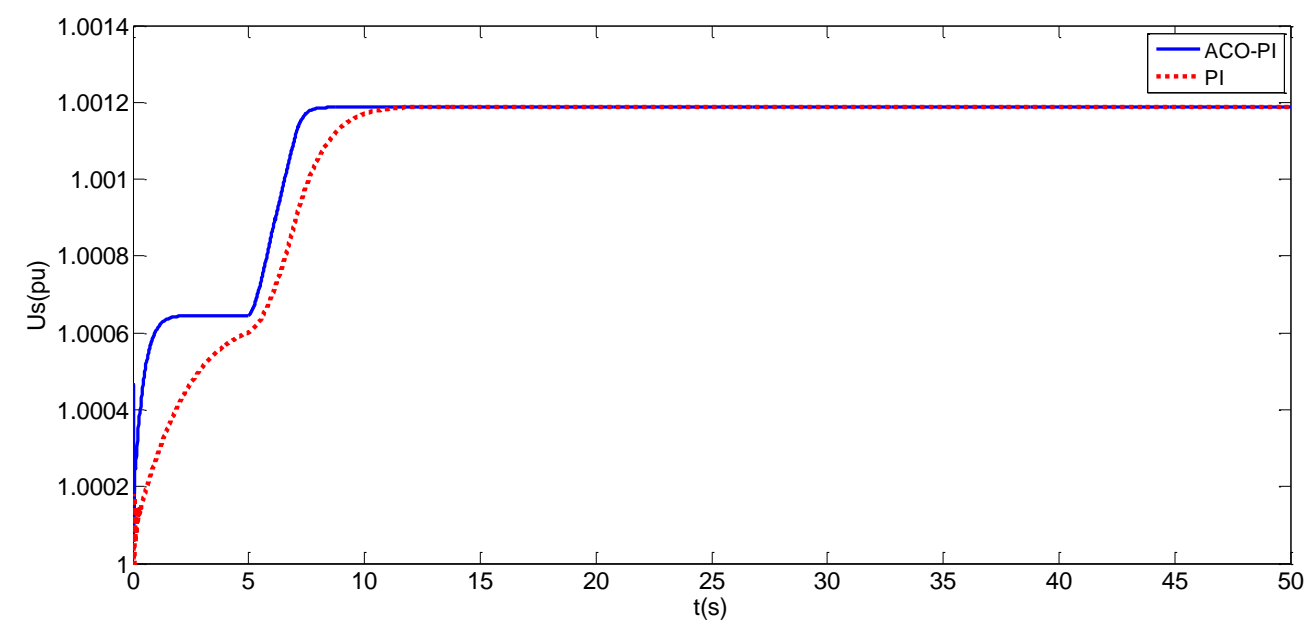

Figure 7. The Dynamic Change Diagram of $U_{s}$ When Wind Speed Changes from $10 \mathrm{~m} / \mathrm{s}$ to $12 \mathrm{~m} / \mathrm{s}$

The simulation results shown that when the wind speed changes from $10 \mathrm{~m} / \mathrm{s}$ to $12 \mathrm{~m} / \mathrm{s}$ at $t=5 \mathrm{~s}$, the self-tuning PI control strategy based on the ant colony optimization algorithm makes the response time of $U_{s} 5.79 \mathrm{~s}$ earlier than the classical PI control algorithm.

When the grid voltage drops $0.1 \mathrm{pu}$ at $t=5 \mathrm{~s}$, the dynamic change diagram of rotor current Idr is shown in Figure 8. The solid line corresponds to the self-tuning PI control strategy based on the ant colony optimization algorithm and its tuned parameters are $K_{p}=1.35$ and $K_{i}=152$. The dotted line corresponds to the classical PI control algorithm and its parameters are $K_{p}=1.25$ and $K_{i}=300$. 


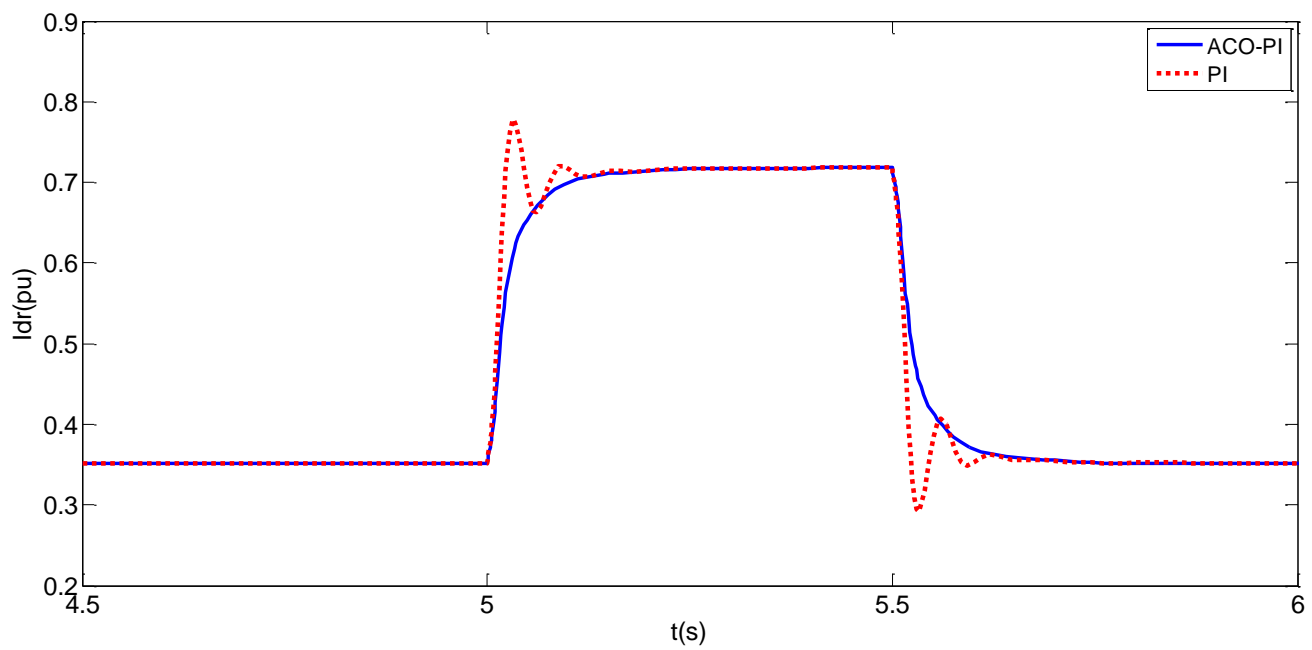

Figure 8. The Dynamic Change Diagram of $I_{d r}$ When the Grid Voltage Drops $0.1 \mathrm{pu}$

The simulation results shown that compared with the classical PI control algorithm, the self-tuning PI control strategy based on the ant colony optimization algorithm has improved the dynamic response characteristics of $I_{d r}$ and reduced the response time when the grid voltage drops $0.1 \mathrm{pu}$.

When the grid voltage drops $0.1 \mathrm{pu}$ at $t=5 \mathrm{~s}$, the dynamic change diagram of terminal voltage $U_{s}$ for wind turbines is shown in Figure 9. The solid line corresponds to the self-tuning PI control strategy based on the ant colony optimization algorithm and its tuned parameters are $K_{p}=1.35$ and $K_{i}=150$. The dotted line corresponds to the classical PI control algorithm and its parameters are $K_{p}=1.25$ and $K_{i}=300$.

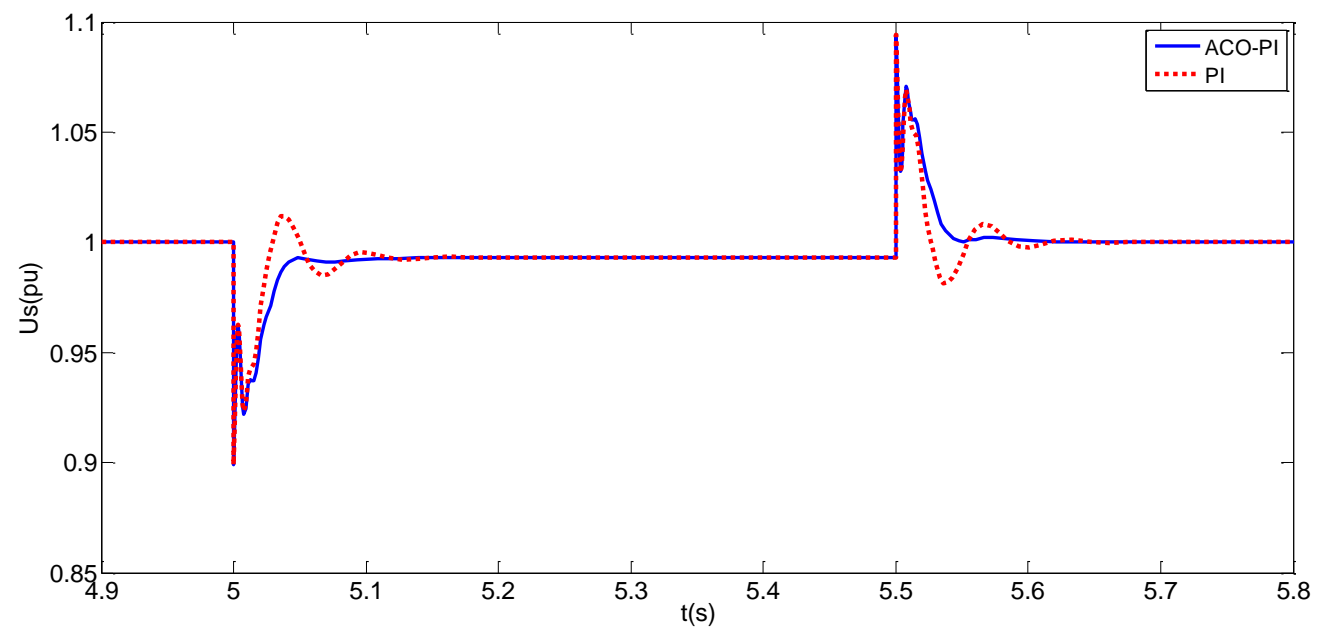

Figure 9. The Dynamic Change Diagram of $U_{s}$ When the Grid Voltage Drops $0.1 \mathrm{pu}$ 
The simulation results shown that compared with the classical PI control algorithm, the self-tuning PI control strategy based on the ant colony optimization algorithm has improved the dynamic response characteristics of $U_{s}$ and reduced the response time when the grid voltage drops $0.1 \mathrm{pu}$.

When the grid voltage drops $0.15 \mathrm{pu}$ at $t=5 \mathrm{~s}$, the dynamic change diagram of rotor current Idr is shown in Figure 10. The solid line corresponds to the self-tuning PI control strategy based on the ant colony optimization algorithm and its tuned parameters are $K_{p}=1.13$ and $K_{i}=210$. The dotted line corresponds to the classical PI control algorithm and its parameters are $K_{p}=1.25$ and $K_{i}=300$.

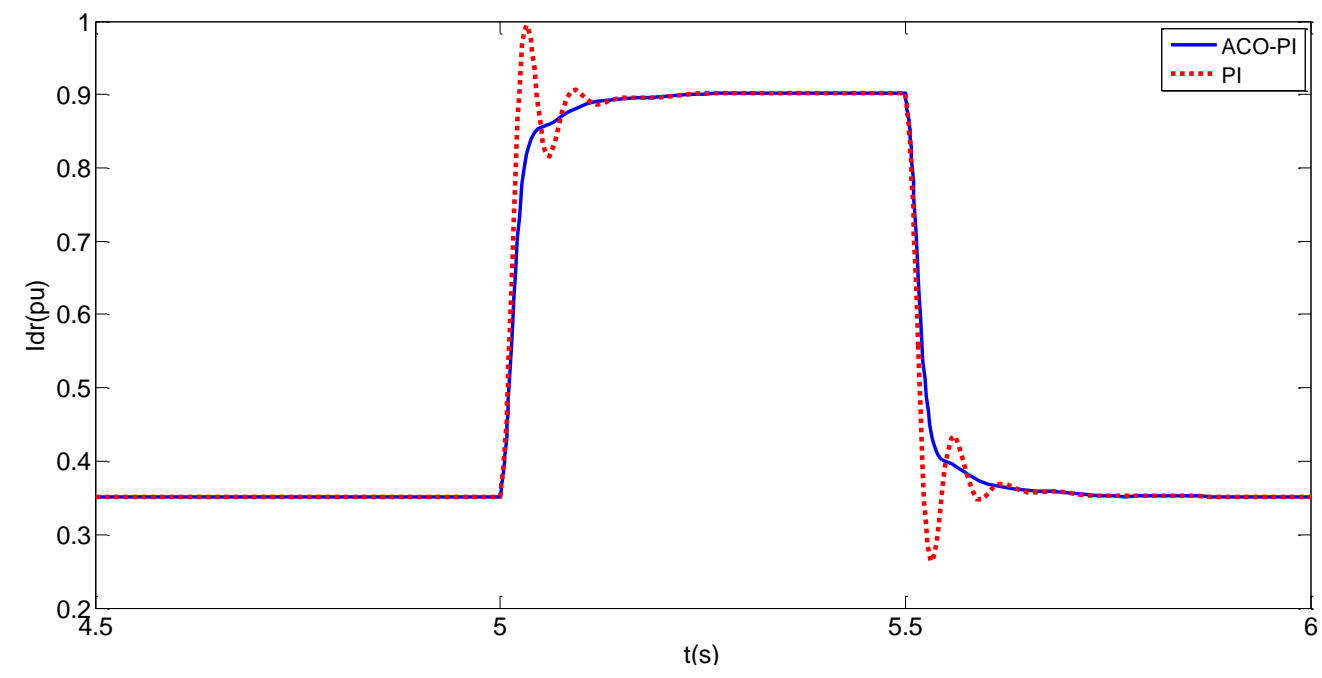

Figure 10. The Dynamic Change Diagram of $I_{d r}$ When the Grid Voltage Drops $0.15 \mathrm{pu}$

The simulation results shown that compared with the classical PI control algorithm, the self-tuning PI control strategy based on the ant colony optimization algorithm has improved the dynamic response characteristics of $I_{d r}$ and reduced the response time when the grid voltage drops $0.15 \mathrm{pu}$.

When the grid voltage drops $0.15 \mathrm{pu}$ at $t=5 \mathrm{~s}$, the dynamic change diagram of terminal voltage $U_{s}$ for wind turbines is shown in Figure 11. The solid line corresponds to the self-tuning PI control strategy based on the ant colony optimization algorithm and its tuned parameters are $K_{p}=1.13$ and $K_{i}=210$. The dotted line corresponds to the classical PI control algorithm and its parameters are $K_{p}=1.25$ and $K_{i}=300$. 


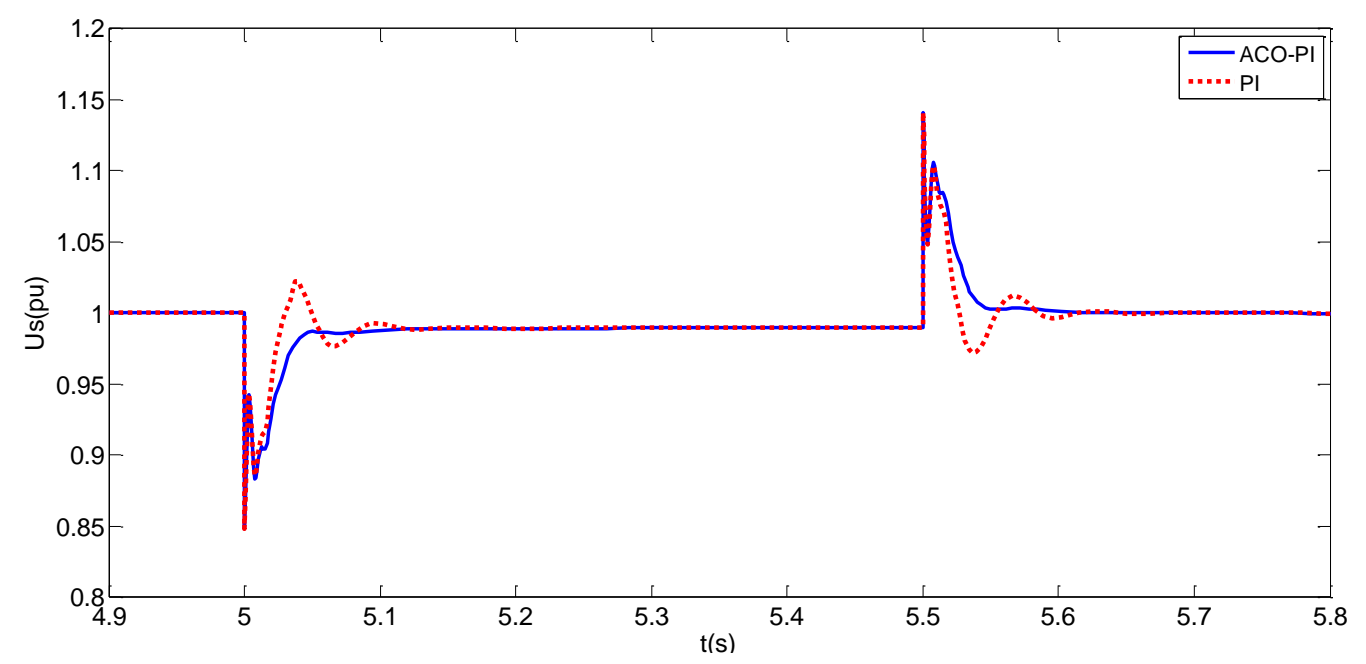

Figure 11. The Dynamic Change Diagram of $U_{s}$ When the Grid Voltage Drops $0.15 \mathrm{pu}$

The simulation results shown that compared with the classical PI control algorithm, the self-tuning PI control strategy based on the ant colony optimization algorithm has improved the dynamic response characteristics of $U_{s}$ and reduced the response time when the grid voltage drops $0.15 \mathrm{pu}$.

\section{Conclusions}

For the shortcoming that the PI controller parameters can't dynamic tuning in constant voltage control system for doubly-fed wind turbines, a PI controller parameters dynamic tuning strategy based on the ant colony optimization (ACO) algorithm is presented. The dynamic and non-dynamic parameter tuning methods are compared and analyzed When the wind speed changes and the grid voltage drops in the system. The following conclusions can be got from the simulation analysis.

(1) When the wind speed changes from $8 \mathrm{~m} / \mathrm{s}$ to $10 \mathrm{~m} / \mathrm{s}$ at $t=5 \mathrm{~s}$, the self-tuning PI control strategy based on the ant colony optimization algorithm makes the response time of $I_{d r} 7.47 \mathrm{~s}$ earlier than the classical PI control algorithm, and makes the response time of $U_{s} 7.61 \mathrm{~s}$ earlier than the classical PI control algorithm.

(2) When the wind speed changes from $10 \mathrm{~m} / \mathrm{s}$ to $12 \mathrm{~m} / \mathrm{s}$ at $t=5 \mathrm{~s}$, the self-tuning PI control strategy based on the ant colony optimization algorithm makes the response time of $I_{d r} 6.91 \mathrm{~s}$ earlier than the classical PI control algorithm, and makes the response time of $U_{s} 5.79 \mathrm{~s}$ earlier than the classical PI control algorithm.

(3) Compared with the classical PI control algorithm, the self-tuning PI control strategy based on the ant colony optimization algorithm has improved the dynamic response characteristics of $I_{d r}$ and $U_{s}$, and reduced the response time when the grid voltage drops $0.1 \mathrm{pu}$ and $0.15 \mathrm{pu}$.

Then simulation results show that the self-tuning PI control strategy based on the ant colony optimization algorithm has improved the stability of the doubly-fed wind turbine and reduced the response time. 


\section{References}

[1] H. G. Zhang, L. Z. Zhang, S. Y. Chen and N. An, "Studies on the Transient Behavior and Dispatching Strategy of Power System Integrated with Large Scale Wind Farms", J. Processing of the CSEE, vol. 27, no. 31, (2007) November, pp. 47-53.

[2] Y. N. Chi, W. S. Wang, Y. H. Liu and H. Z. Dai, "Impact of Scale Wind Farm Integration on Power System Transient Stability", J. Automation of Electric Power System, vol. 30, no. 15, (2006) August, pp. 10-14.

[3] Y. F. Ren and Z. Q. An, "The Flexible Grid-connected Operation and Control of the Doubly-fed Wind Turbines", China Machine Press, Beijing, China, (2011).

[4] H. Z. Cheng and H. Wu, "Reactive Power and Voltage Stability of Power System", China Electric Power Press, Beijing, China, (2004).

[5] R. Pena, J. C. Clare and G. M. Asher, "Doubly Fed Induction Generator Using Back-to-back PWM Converter and Its Application to Variable-speed Wind-energy Generation", J. IEE Proceedings: Electric Power Application, vol. 143, issue. 3, (1996) May, pp. 231-241.

[6] Y. F. Fan, Q. Chao and Y. Gao, "Simulation of Influence of Large Double-fed Variable Speed Wind Turbine into Grid”, J. Power System Protection and Control, vol. 36, no. 16, (2008) August, pp. 30-32.

[7] Z. J. Yang, H. B. Wu, M. Ding and J. Liu, "Control Strategy of Doubly-fed Wind Generation System for Power Grid Fault", J. Power System Protection and Control, vol. 38, no. 1, (2010) January, pp. 14-18.

[8] K. Hee-Sang, S. Bruey, J. Jatskevich, G. Dumont and A. Moshref, "A PI Control of DFIG Based Wind Farm for Voltage Regulation at Remote Location”, Proceedings of 2007 IEEE Power Engineering Society General Meeting, (2007) June, pp. 1-6.

[9] F. Mwasilu, J. J. Justo, K. S. Ro and J. W. Jung, "Improved of Dynamic Performance of Doubly Fed Induction Generator Based Wind Turbine Power System under an Unbalanced Grid Voltage Condition”, J. IET Renewable Power Generation, vol. 6, issue. 6, (2012) November, pp. 424-434.

[10] R. Li, F, Tang, Y. P. Liu and Y. Q. Ke, "Improved Constant Voltage Control of DFIG Based Wind Farm", J. Power System Protection and Control, vol. 40, no. 6, (2012) March, pp. 79-85.

[11] O. Anaya-Lara, N. Jenkins, J. Ekanayake, P. Cartwright and M. Hughes, "Wind Energy Generation: Modeling and Control", A John Wiley and Sons, Ltd, New York, USA, (2009).

[12] K. Verbeeck and A. Nowe, "Colonies of Learning Automata", J. IEEE Transactions on Systems: Man and Cybernetics Part B, vol. 32, issue. 6, (2002) December, pp. 772-780.

[13] X. J. Chen, T. K. Ding and Z. Zhang, "Ant Colony Algorithm for Solving Fault Location in Distribution Networks", J. Automation of Electric Power System, vol. 30, no.5, (2006) March, pp. 74-77.

[14] H. B. Zhai, H. Z. Cheng, G. Y. Lü, C. L. Chen, F. Q. Jiang and L. F. Fang, "Parallel ant colony algorithm in multistage transmission network optimal planning", J. Automation of electric power system, vol. 28, no.20, (2004) October, pp. 37-42.

[15] B. Berbaoui, C. Benachaiba, M. Rahli and H. Tedjini, "An Efficient Algorithm to Tuning PI Controller Parameters for Shunt Active Power Filters Using Ant Colony Optimization", J. Przeglad Elektrotm, vol. 87, no. 6, (2011) June, pp. 140-145.

[16] J. G. Ziegler and N. B. Nichols, "Optimum Settings for Automatic Controllers", J. Trans ASME, vol. 64, no.10, (1942) November, pp. 759-768. 